\title{
Technetium-99m chelator-free radiolabeling of specific glutamine tumor imaging nanoprobe: in vitro and in vivo evaluations
}

This article was published in the following Dove Press journal:

International Journal of Nanomedicine

\author{
Seyedeh Masoumeh \\ Ghoreishi, ${ }^{1,2}$ Ali Khalaj,' Omid \\ Sabzevari, ${ }^{3}$ Leila Badrzadeh, \\ Pardis Mohammadzadeh, 1,4 \\ Seyed Shahaboddin Mousavi \\ Motlagh, ${ }^{5}$ Ahmad Bitarafan- \\ Rajabi, ${ }^{6}$ Mehdi Shafiee \\ Ardestani ${ }^{\prime}$ \\ 'Department of Radiopharmacy, Faculty \\ of Pharmacy, Tehran University of Medical \\ Sciences, Tehran, Iran; ${ }^{2}$ Cancer Research \\ Center, Health Research Institute, Babol \\ University of Medical Sciences, Babol, \\ Iran; ${ }^{3}$ Department of Toxicology and \\ Pharmacology, Faculty of Pharmacy, \\ Toxicology and Poisoning Research Centre, \\ Tehran University of Medical Sciences, \\ Tehran, Iran; ${ }^{4}$ Department of Genetics \\ and Molecular Biology, Isfahan University \\ of Medical Sciences, Isfahan, Iran; \\ ${ }^{5}$ Biotechnology Department of Iranian \\ Food and Drug Administration, Ministry \\ of Health, Tehran, Iran; ${ }^{6}$ Echocardiography \\ Research Center, Cardiovascular \\ Interventional Research Center, \\ Department of Nuclear Medicine, \\ Rajaie Cardiovascular Medical and \\ Research Center, Iran University of \\ Medical Sciences, Tehran, Iran
}

Correspondence: Ahmad Bitarafan-Rajabi Echocardiography Research Center, Cardiovascular Interventional Research Center, Department of Nuclear Medicine, Rajaie Cardiovascular Medical and Research Center, Iran University of Medical Sciences,

Tehran, Iran

Email bitarafan@hotmail.com

Mehdi Shafiee Ardestani

Department of Radiopharmacy, Faculty of Pharmacy, Tehran University of Medical Sciences, Revolution Square, 16 Azar St,

Tehran, Iran

Tel +98 2I 22048173

Email shafieeardestani@tums.ac.ir
Introduction: Nowadays, molecular imaging radiopharmaceuticals', nanoparticles', and/or small-molecule biomarkers' applications are increasing rapidly worldwide. Thus, researchers focus on providing the novel, safe, and cost-effective ones.

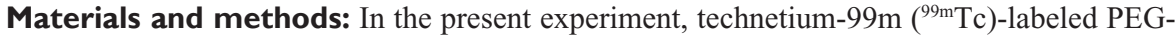
citrate dendrimer- $\mathrm{G}_{2}$ conjugated with glutamine (nanoconjugate) was designed and assessed as a novel tumor imaging probe both in vitro and in vivo. Nanoconjugate was synthesized and the synthesis was confirmed by Fourier transform infrared, proton nuclear magnetic resonance, liquid chromatography-mass spectrometry, dynamic light scattering, and static light scattering techniques. The toxicity was assessed by XTT and apoptosis and necrosis methods.

Results: Radiochemical purity indicates that the anionic dendrimer has a very high potential to complex formation with ${ }^{99 \mathrm{~m}} \mathrm{Tc}$ and is also very stable in the human serum in different times. Results from the imaging procedures showed potential ability of nanoconjugates to detect tumor site.

Conclusion: Suitable features of the anionic dendrimer show that it is a promising agent to improve nanoradiopharmaceuticals.

Keywords: biodegradable, biocompatible, dendrimer, glutamine, chelator free, radiolabeling

\section{Introduction}

Cancer has remained as a major health problem, and most of the people who are diagnosed with cancer each year eventually die from the disease. ${ }^{1}$ Due to the vast growth of the patient population with the cancer risk and costs of health care, nuclear medicine is developed for early detection and prevention of the cancer. To achieve these goals, scientists have focused on the treatment and diagnosis of the malignancies. Noninvasive cancer imaging techniques that revolutionized current diagnostic paradigms, such as single-photon emission computed tomography (SPECT) and positron emission tomography (PET), are used for the detection of biologic processes by involving high-sensitivity radiotracers. ${ }^{2}$ In clinical applications, Technetium-99m-based contrast agents are the most routine radiotracers for SPECT imaging. ${ }^{3-5}$ Technetium- $99 \mathrm{~m}$ $\left({ }^{99} \mathrm{~m} \mathrm{Tc}\right)$ has received considerable attention because of its appropriate 6-hour half-life, good coordination chemistry, availability, acceptable gamma ray energy, and isomeric transition decay to very long-lived nuclide. ${ }^{6}$

In the recent years, the nanostructure carrier properties are very valuable. For instance, their large surface area compared to their volume and the diversity of their surface chemistries lead to designing these materials. ${ }^{7,8}$ Although most imaging agents in the clinic are small-molecule compounds, biocompatible nanocarriers have drawn the researchers' attention for their characteristics and application in molecular 
imaging. ${ }^{9}$ Dendrimers are extensively ideal carriers in nuclear medical imaging, ${ }^{10}$ thanks to their low polydispersity, three-dimensional globular shapes, and their numerous branches. ${ }^{11}$ In this framework, Zhang et al have reported the PEGylated dendrimer poly (amidoamine) (PAMAM)-folic acid conjugates and radiolabeled with ${ }^{99 \mathrm{~m}} \mathrm{Tc}$. The radioconjugate showed high uptake in KB cancer cells. ${ }^{12}$ The use of PAMAM dendrimer as a radiotracer for SPECT imaging and radiotherapy of gliomas has been introduced by Zhao et al. ${ }^{13}$ Sato et al described PAMAM dendrimers labeled with ${ }^{111}$ In and conjugated to antisense oligonucleotides for tumor targeting in human ovarian cancer-bearing mice model. Results showed elevation in accumulation inside the tumors. ${ }^{14}$ Moreover, Seo and his colleagues synthesized the unique LyP-1-dendrimer labeled with ${ }^{64} \mathrm{Cu}$ for PET/CT imaging of atherosclerotic plaque to enhance accumulation of the contrast agent with a monomeric peptide. ${ }^{15}$ In this paper, a novel anionic citric acid-based PEG dendrimer, which eliminates the need of conjugation with chelators, is introduced. Synthesis of the dendrimer was pioneered by Namazi and Adeli ${ }^{16}$ and then modified by Ardestani et al and various biologic assays were done. ${ }^{17-19}$ Unique features that make the anionic dendrimer a suitable carrier compared to PAMAM include biocompatibility, biodegradability, ${ }^{20}$ higher water solubility, ${ }^{21}$ the capability of citric acid to form a complex with ${ }^{99 \mathrm{~m}} \mathrm{Tc},{ }^{22}$ availability of raw materials, and low cost. Furthermore, the negative charge of the dendrimer protects against surface toxic interactions between the labeled conjugate and the normal cell. ${ }^{23}$

Amino acids represent an important class of nutrients for cancerous cells because of their high proliferation rate. ${ }^{24}$ Glutamine is a nonessential amino acid that plays many critical rules in mammalian metabolism. In addition to the role of glutamine in protein synthesis as a nitrogen donor, it is participating in biologic processes. For example, it is an intermediate compound in the tricarboxylic acid (TCA) cycle, a suppressing oxidative stress amino acid for restoring glutathione's reduced form and a mammalian target of rapamycin activator. ${ }^{25,26}$ A particular specification of glutamine that has a dramatic role in some metabolic pathways and that can cause the cancerous cells to have high glutamine consumption rate is glutamine addiction. ${ }^{27}$ Recently, researchers have reported that the abovementioned application of glutamine has various benefits for selective delivering of therapeutic or diagnostic agents to the tumor site. ${ }^{28-30}$ Therefore, in this research for the first time, synthesis of the novel nanoconjugate was developed. The most important aim of this study was chelator-free radiolabeling with technetium-99m and targeting cancer cells by using a noncytotoxic, low-molecular-weight/cost and negatively charged nanosized carrier.

\section{Materials and methods}

All chemical reagents were of analytical grade and used without further purification. Polyethylene glycol diacid 600 was purchase from Merck (Darmstadt, Germany). Citric acid, N, $\mathrm{N}^{\prime}$-dicyclohexylcarbodiimide (DCC), and L-glutamine t-butyl ester hydrochloride were purchased from Sigma-Aldrich Co. (St Louis, MO, USA). An infrared spectrum was measured on Perkin Elmer Spectrum BX-II spectrometer. ${ }^{1} \mathrm{H}-\mathrm{NMR}$ spectra were measured in dimethyl sulfoxide- $\mathrm{d}_{6}\left(\right.$ DMSO- $\left._{6}\right)$ by a Bruker $500 \mathrm{MHz}$ instrument (Billerica, Massachusetts, Germany). A liquid chromatography-mass spectrometry (LC-MS) analysis was provided by Agilent 6410 Triple Quadrupole LC-MS. Static light scattering (SLS) technique was performed using Zetasizer ZSP (Nano-ZSP, Malvern Instruments, Malvern, UK) instrument. Atomic force microscopy (AFM) analysis was performed by JPK Nanowizard II. Dynamic light scattering (DLS) was measured by Malvern nano-zs. Annexin-V FLUOS staining kit was purchased from Roche (Basel, Switzerland) and XTT powder from Sigma-Aldrich Co. A549 and HEK-293 cell lines were obtained from the Pasteur Institute (Tehran, Islamic Republic of Iran). Female nude mice (20-28 g) bearing A549 tumor in the neck region used for imaging and biodistribution studies were purchased from Pasteur Institute of Tehran. The inductions of tumor were based on the published article..$^{31}$ The mice were housed under sterile conditions of controlled temperature $\left(22^{\circ} \mathrm{C} \pm 2^{\circ} \mathrm{C}\right)$ and humidity (45\%-65\%). Sterile food and water were fed to the mice. Biodistribution studies were done in triplicate. All animal experiments were approved by the Animal Experimental Committee of Tehran University of Medical Sciences (number IR.Tums.REC.1394.1509) and all procedures were performed in accordance with the National Institutes of Health Guidelines for the Care and Use of Laboratory Animals.

\section{Chemical synthesis of dendrimer- $\mathrm{G}_{2}$ and conjugation by glutamine}

Dendrimer- $\mathrm{G}_{2}$ (second generation) was prepared as described previously. ${ }^{32}$ Based on the previous method, PEG diacid 600 was dissolved in DMSO followed by addition of DCC to the solution. Then, citric acid as the monomer was added to generate the $G_{1}$ (first generation). Then the product was purified by dialysis bag; dendrimer- $\mathrm{G}_{1}$ was coupled to citric acid in DMSO to produce the $\mathrm{G}_{2}$ with the use of DCC. Subsequently, dendrimer-glutamine conjugate was prepared in $70 \%$ yield by the following method. Briefly, $0.05 \mathrm{~g}$ dendrimer was 
dissolved in DMSO $(\mathrm{pH}=7)$ to react with L-glutamine t-butyl ester hydrochloride $(0.17 \mathrm{~g})$ in the presence of DCC $(0.74$ g). The reactants were constantly stirred for 4 days at room temperature to react completely with the carboxylate terminal groups of dendrimer. Afterwards, $\mathrm{HCl}(0.1 \%)$ was added to the solution to remove the protecting group of glutamine. A dialysis bag (cutoff $500-1,000 \mathrm{Da}$ ) was used to purify the reaction product against deionized water for 2 days.

\section{Molar mass measurement of the conjugate using SLS}

For molar mass measurement, SLS technique was performed as follows: five different concentrations of the conjugate $(1,0.8,0.6,0.4$, and $0.2 \mathrm{mg} / \mathrm{mL})$ were prepared in deionized prefiltered water at room temperature and then filtered $(0.22 \mu \mathrm{m})$. The comparison between the conjugate's and dendrimer's molecular weight (reported previously ${ }^{17}$ ) disclosed the perfect synthesis of conjugation process.

\section{${ }^{99 \mathrm{~m}} \mathrm{Tc}$ radiolabeling of dendrimer- glutamine conjugate}

For radiolabeling, a lyophilized kit was prepared. For this purpose, $10 \mathrm{mg}$ nanoconjugate was dissolved in $2 \mathrm{~mL}$ distilled water in a glass vial. Then $0.3 \mathrm{~mL}$ tin chloride solution $(1 \mathrm{mg} / 1 \mathrm{~mL}$ ) and $0.4 \mathrm{~mL}$ ascorbic acid (antioxidant agent, $5 \mathrm{mg} / 1 \mathrm{~mL}$ ) were added, $\mathrm{pH}$ was adjusted to be 8 , and then the complex was lyophilized. To that, $370 \mathrm{MBq}^{99 \mathrm{~m}} \mathrm{TcO}_{4}^{-}$ obtained from ${ }^{99} \mathrm{Mo} /{ }^{99 \mathrm{~m}} \mathrm{Tc}$ generator was added and incubated after 10 minutes at room temperature.

\section{Radiochemical purity}

Radiochemical purities (RCPs) of the ${ }^{99 \mathrm{~m}} \mathrm{Tc}$ nanoconjugate were analyzed by Whatman paper as solid phases and acetone/methanol (1:1) and saline as mobile phases. The abovementioned method is a rapid and simple methodology mentioned in references ${ }^{33,34}$ and may be substituted for the time-consuming method to save time. For determination of radiochemical impurity $\left({ }^{99 \mathrm{~m}} \mathrm{TcO}_{2}\right.$, free pertechnetate) $6 \mu \mathrm{L}$ samples were spotted at the origin of two paper strips $(1.2 \times 10 \mathrm{~cm})$. The strips were developed in solvents. Then, the strips were cut into two parts and the radioactivity in each segment was determined in a $\gamma$ well-type counter. By the use of acetone/methanol, ${ }^{99 \mathrm{~m}} \mathrm{TcO}_{2}$ and radiolabeled nanoconjugate remains in the origin and free pertechnetate move with the solvent. Thus, the percentage of free pertechnetate was calculated. With saline, ${ }^{99 \mathrm{~m}} \mathrm{TcO}_{2}$ remains in the origin and ${ }^{99 \mathrm{~m}} \mathrm{Tc}$ nanoconjugate and free pertechnetate move with the solvent. Thus, the percentage of ${ }^{99} \mathrm{TcO}_{2}$ was obtained. Finally, RCP was assessed by the following formula:

$$
\mathrm{RCP}=100-\left(\text { free pertechnetate }+{ }^{99 \mathrm{~m}} \mathrm{TcO}_{2}\right)
$$

\section{XTT assay}

XTT is one of the colorimetric assays that are used to assess cell viability based on metabolic activity. This assay is based on the reduction of the yellow tetrazolium salt (XTT) to a more colored formazan dye by dehydrogenase enzymes in metabolically active cells. An electron coupling reagent such as PMS (N-methylphenazonium methyl sulfate) can significantly improve the efficiency of XTT reduction in cells..$^{35}$ At the end of the incubation times (24 and 48 hours), XTT/ PMS (50:1 $\mu \mathrm{L})$ was added to each well of 96-well plate that contained 10,000 cells. Then, the plate was returned to incubator for 2 hours. The soluble formazan dye was measured at a wavelength of $450 \mathrm{~nm}$ using a spectrophotometer. The results were compared to the untreated cell cultures (control).

\section{In vitro apoptosis/necrosis assay}

For apoptosis/necrosis detection, the Annexin V-propidium iodide (PI) staining kit (Roche) was used according to the manufacturer's instruction. A549 cells $\left(\sim 4 \times 10^{6}\right.$ cells) were seeded in the six-well cell culture plates. After 24 hours, A549 cells $\left(\sim 2 \times 10^{6}\right.$ cells $)$ were treated with $100 \mu \mathrm{m}$ of nanoconjugate $(5.5 \mathrm{mg} / \mathrm{mL})$ and were incubated for 48 hours. After incubation the supernatant was collected and the adherent cells were trypsinized. Then the cells were collected, centrifuged, and washed twice with PBS. Subsequently, about $10^{6}$ cells were incubated with Annexin V-PI reagent buffer for 15 minutes at room temperature and then analyzed with flow cytometry.

\section{Lipophilicity and stability test}

For estimating the lipophilicity $(\log P)$ of radiolabeled nanoconjugate, $200 \mu \mathrm{L}$ of the radiolabeled compound was added to the test tube containing suspension of $2 \mathrm{~mL} n$-octanol in $2 \mathrm{~mL}$ normal saline. The solution was mixed at room temperature in a shaker for 1 hour. Then, $500 \mu \mathrm{L}$ solution of each phase was withdrawn and radioactivity was counted using a $\gamma$ well-type counter. Lipophilicity was assessed by the following formula:

$$
\log P=\log \left(\frac{\text { Activities in } n \text {-octanol }}{\text { Activities in normal saline }}\right)
$$

In vitro stability test was performed to assess the labeling efficiency of the complex at different time intervals up to 
24 hours. Three hundred microliters of radiolabeled conjugate was incubated in $600 \mu \mathrm{L}$ of human serum at $37^{\circ} \mathrm{C}$ and in $600 \mu \mathrm{L}$ of PBS at room temperature, then $100 \mu \mathrm{L}$ of trichloroacetic acid $10 \%$ was added in solution and serum proteins were separated by centrifugation. Labeling efficiency in plasma was analyzed by chromatography.

\section{Scintigraphic images}

For SPECT imaging, all mice were anesthetized with ketamine. Then $3.7 \mathrm{MBq}^{99 \mathrm{~m}} \mathrm{Tc}$ nanoconjugate was injected into nude mice bearing A549 tumor through the tail vein $(n=3)$. Afterwards, the anesthetized mice were horizontally placed under the SPECT/CT imaging system (Siemens, SimbiaT $_{2}$ equipped with low energy high-resolution collimators). Images were acquired at 3 hours after injection using a $256 * 256$ matrix size with a $20 \%$ energy window set at $140 \mathrm{keV}$. The blocking studies were done with coinjection of unlabeled glutamine $(10 \mathrm{mg} / \mathrm{mL})$ and ${ }^{99 \mathrm{~m}} \mathrm{Tc}$ nanoconjugate.

\section{Biodistribution studies}

Before the injection of radioactive agents, animals were anesthetized by intraperitoneal injection of ketamine $(n=3)$. Then 3.7 MBq of the labeled complex was injected intravenously in the tail. The mice were killed and different organs were removed and washed with normal saline to clean their surface from blood and residues. Blood was collected by cardiac puncture and activity in each organ was measured with calibrated gamma counter. Radiotracer percentage dose was obtained from activities counted (dose per gram of tissue) in each organ divided by total activities.

\section{Statistical analysis}

Statistical data analysis was done using Prism 5 and Excel software (Microsoft Office 2013). For quantitative data analysis one-way analysis of variance followed by Tukey's test was applied. $P<0.05$ was considered statistically significant.

\section{Results}

\section{Characterization of dendrimer-glutamine conjugate}

Synthesis of the $\mathrm{G}_{2}$ dendrimer and the conjugation process have been described earlier. Schematic illustration of the chemical synthesis of dendrimer- $\mathrm{G}_{2}$ and conjugation with glutamine is shown in Scheme 1. Fourier transform infrared (FT-IR) spectra are presented in Figure 1. FT-IR spectrum wavenumbers of dendrimer- $\mathrm{G}_{2}: 3,430(\mathrm{OH})$, 2,924 (CH stretching), 1,726 (CO carbonyl) $\mathrm{cm}^{-1}$. FT-IR spectrum wavenumbers of nanoconjugate: 3,403 (OH), 2,922
(CH stretching), 1,624 (CO carbonyl), 1,104 (C-N) $\mathrm{cm}^{-1}$. FT-IR spectrum wavenumbers of glutamine: 1,687 (CO carbonyl), 3,300 $\left(\mathrm{NH}_{2}\right), 1,410(\mathrm{CN}), 3,000(\mathrm{OH}) \mathrm{cm}^{-1}$. ${ }^{1} \mathrm{H}-\mathrm{NMR}$ of dendrimer-G $\mathrm{G}_{2}\left(500 \mathrm{MHz}, \mathrm{DMSO}-\mathrm{d}_{6}\right): \delta_{\mathrm{H}}=2.7$ (dd, ${ }^{2} \mathrm{~J}=15.5 \mathrm{~Hz}, 2$ hours, $\left.\underline{\mathrm{CH}}_{2} \mathrm{COO}\right), 3.4$ ( $\mathrm{t},{ }^{3} \mathrm{~J}=5 \mathrm{~Hz}, 2$ hours, $\underline{\mathrm{OCH}}_{2} \mathrm{CH}_{2}$ ), 5.02 (s, 2 hours, $\underline{\mathrm{OCH}}_{2} \mathrm{CO}$ ), nanoconjugate $\left(500 \mathrm{MHz}, \mathrm{DMSO}-\mathrm{d}_{6}\right): \delta_{\mathrm{H}}=1.78\left(\mathrm{~m}, 4\right.$ hours, $\underline{\mathrm{CH}}_{2} \underline{\mathrm{CH}}_{2} \mathrm{CO}$ glutamine), $2.2\left(\mathrm{dd},{ }^{2} \mathrm{~J}=6.7 \mathrm{~Hz}, 2\right.$ hours, $\left.\underline{\mathrm{CH}}_{2} \mathrm{COO}\right), 3.4$ (t, ${ }^{3} \mathrm{~J}, 2$ hours, $\left.\mathrm{OCH}_{2} \mathrm{CH}_{2}\right), 3.5$ (t, ${ }^{3} \mathrm{~J}, 1$ hour, $\mathrm{CH}_{2} \underline{\mathrm{CHNH}}$ ), 6.9 (s, 1 hour, $\mathrm{CHNHCO}$ ), 7.5 (s, 2 hours, $\mathrm{CONH}_{2}$ ), and glutamine $\left(500 \mathrm{MHz}, \mathrm{D}_{2} \mathrm{O}\right): \delta_{\mathrm{H}}=2.14\left(\mathrm{t},{ }^{3} \mathrm{~J}, 2\right.$ hours, OOC $\underline{\mathrm{CH}}_{2} \mathrm{CH}_{2}$ ), 2.44 (q, ${ }^{4} \mathrm{~J}, 2$ hours, $\mathrm{CH}_{2} \underline{\mathrm{CH}}_{2} \mathrm{CH}$ ), 3.78 (t, ${ }^{3} \mathrm{~J}$, 2 hours, $\mathrm{CH}_{2} \underline{\mathrm{CH}}$ ) are presented in Figure 2. Figure 2D showed the ${ }^{13} \mathrm{C}$-NMR of nanoconjugate. LC-MS for a precise confirmation of nanoconjugate is displayed in Figure 3. The obtained chemical structure of the conjugate is in agreement with our approximation. The average molecular weight for the nanoconjugate was $2.93 \pm 0.375 \mathrm{kDa}$ and Debye plot is showed in Figure 4. Moreover, previous studies reported the average molecular weight of intact dendrimer- $\mathrm{G}_{2}$, which was $2 \mathrm{kDa}$. By comparing the molecular weights of dendrimer- $\mathrm{G}_{2}$, glutamine, and the nanoconjugate, the average efficacy of conjugation process is predictable to be $6: 1$ (glutamine:dendrimer- $\mathrm{G}_{2}$ ) molar ratio per particle.

\section{The size, zeta potential, and surface morphology of the conjugate}

The average size and zeta potential of the conjugate were determined by DLS techniques, which are $52.2 \mathrm{~nm}$ and $-14 \mathrm{mV}$, respectively. Size and zeta potential of the conjugate and intact dendrimer (11.8 nm and $-9.92 \mathrm{mV}$ ) are shown in Figure 5. In our previous study, particle size of dendrimer- $\mathrm{G}_{2}$ was determined to be $91 \mathrm{~nm} .{ }^{32}$ Decreased particle sizes in this study were achieved by adding $\mathrm{NaOH}$ and reaching the $\mathrm{pH}$ from 5 to 8 . Increasing the $\mathrm{pH}$ leads to the formation of anionic groups, repulsion, and prevents the accumulation of particles. The nanoconjugate exhibits a narrow size distribution. Surface morphology and size of the nanoconjugate and intact dendrimer were characterized by AFM technique. Two-dimensional (2D) and 3D images of dendrimer- $\mathrm{G}_{2}$ and nanoconjugate are presented in Figure 6.

\section{XTT assay}

The XTT test was performed on A549 and HEK-293 cell lines for nanoconjugate at $0.2,0.4,0.84,1.68,3.37,6.75$, $13.5 \mathrm{mg} / \mathrm{mL}$ concentrations, and the viability values versus concentrations are shown in Figure 7 . In both cancer and normal cell lines, at 24 hours a rise is seen in the mitochondrial activity of the cells at the concentration up to 


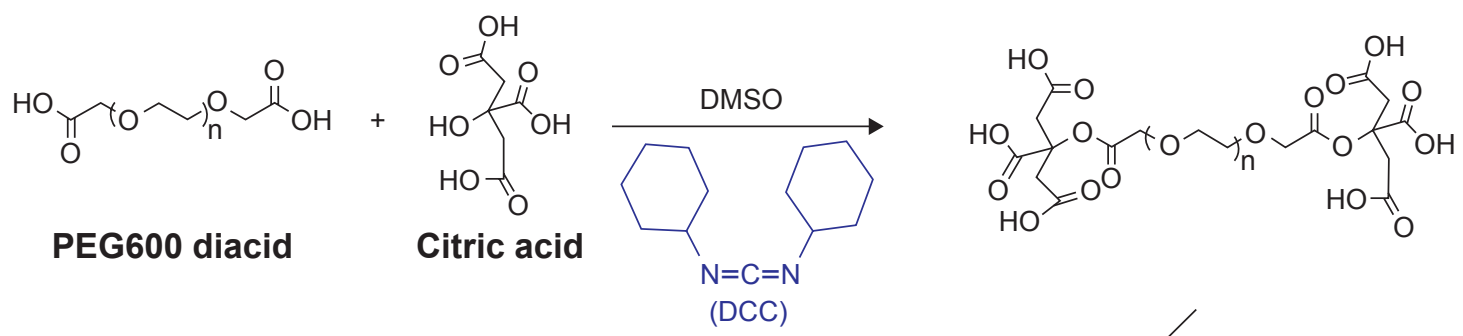

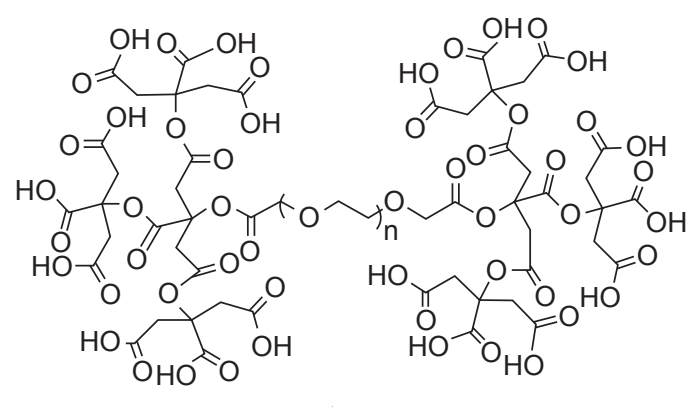<smiles>CC(C)(C)OC(=O)[C@H](N)CCC(N)=O</smiles>
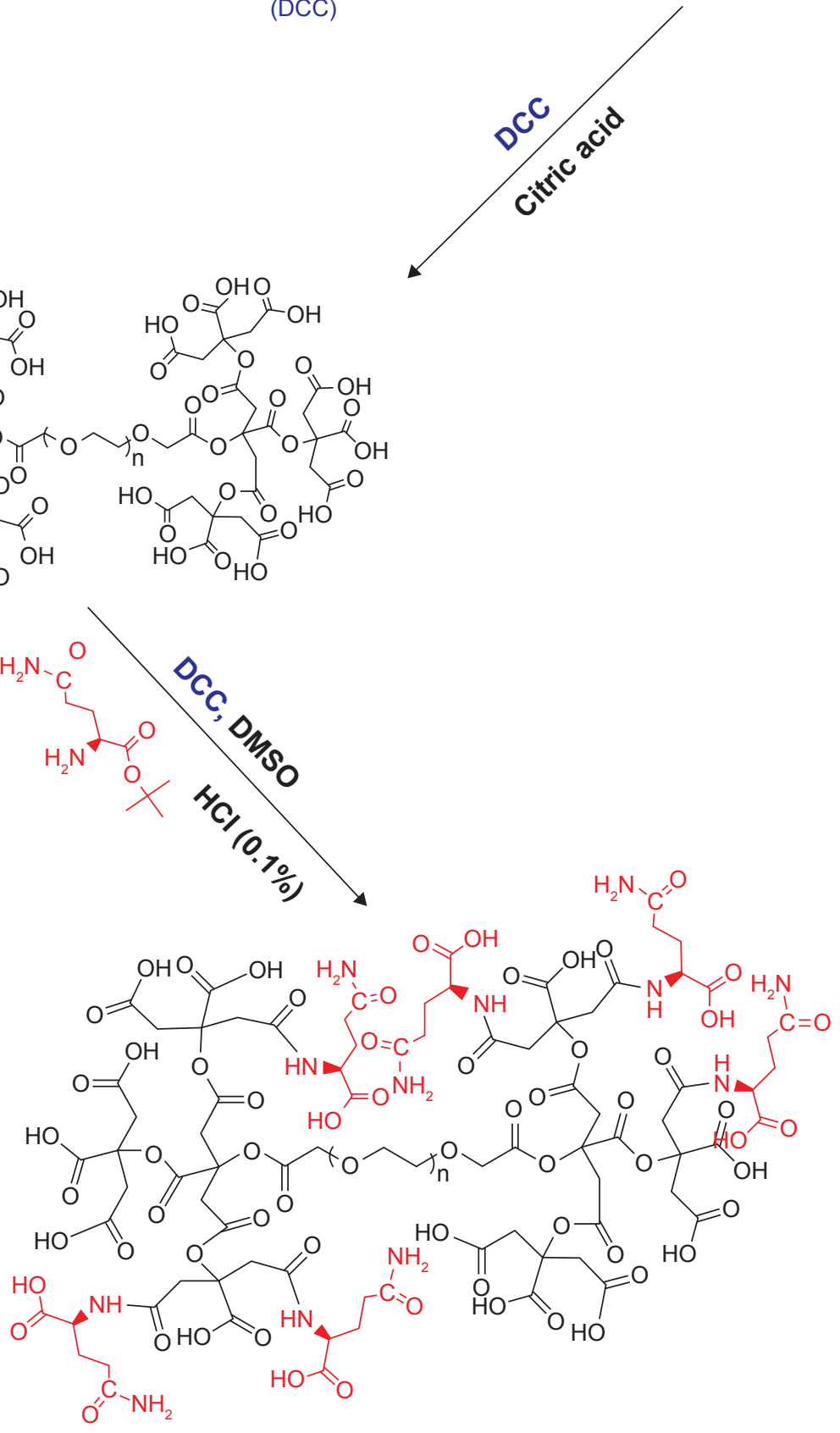

Scheme I The preparation routes of dendrimer- $G_{2}$ and glutamine conjugation. Abbreviations: DCC, N, N'-dicyclohexylcarbodiimide; DMSO, dimethyl sulfoxide.

$13.5 \mathrm{mg} / \mathrm{mL}$. After 48 hours of incubation, a noteworthy enhancement can be noticed in the mitochondrial activity of the cells. All in all, exposure of A549 and HEK-293 cell lines to the nanoconjugate for 24 and 48 hours showed no significant toxicity $(P<0.05)$.

\section{Apoptosis-necrosis assays}

At the end of the treatment of the A549 cell line at the $5.5 \mathrm{mg} / \mathrm{mL}$ nontoxic concentration (Figure 8), the amounts of necrosis and apoptosis were low. These observations were in harmony with the cell cytotoxicity data. 


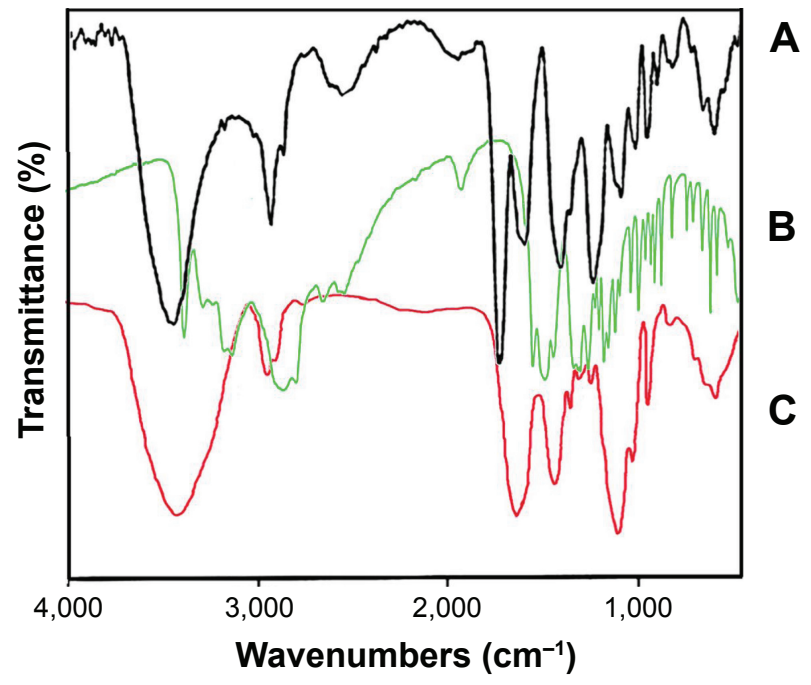

Figure I Fourier transform infrared spectrum of $(\mathbf{A})$ dendrimer- $\mathrm{G}_{2},(\mathbf{B})$ glutamine, and $(\mathbf{C})$ dendrimer-glutamine.

\section{Radiolabeling and quality control of ${ }^{99 m}$ Tc dendrimer-glutamine}

Radiolabeling is accomplished by adding sodium pertechnetate to the kit vial. As the structure of ${ }^{99 \mathrm{~m}} \mathrm{Tc}$ dendrimer is
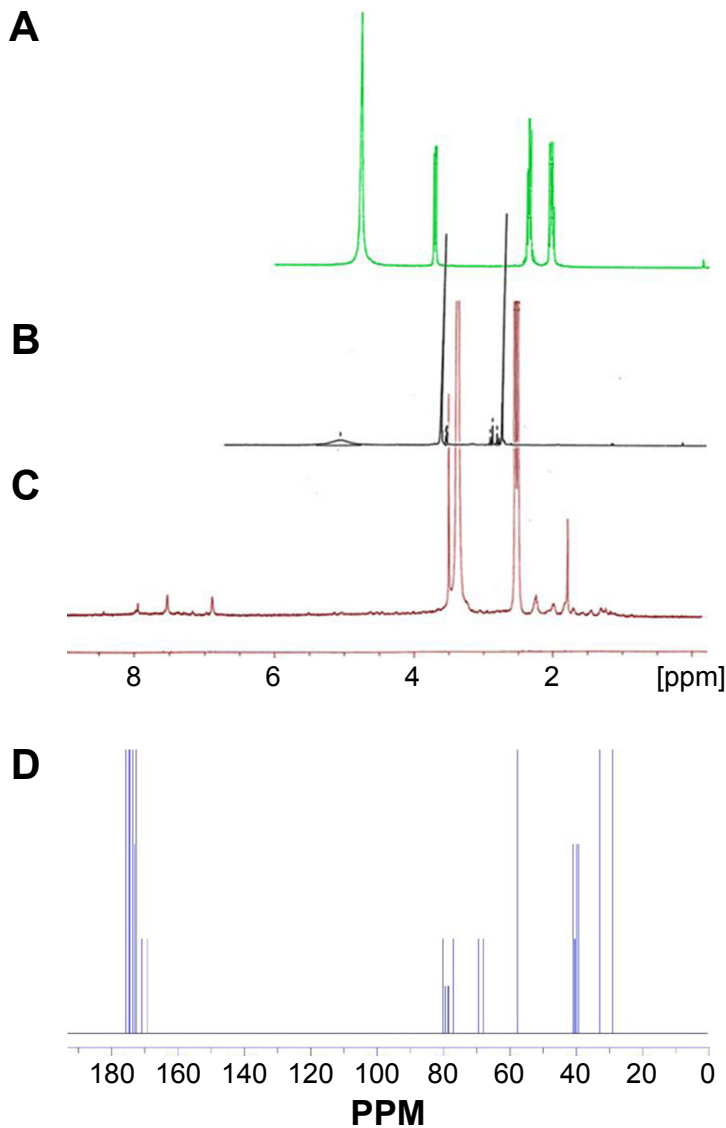

Figure 2 The 'H-NMR spectrum of $(\mathbf{A})$ glutamine, $(\mathbf{B})$ dendrimer- $\mathrm{G}_{2}$, (C) dendrimerglutamine, and (D) ${ }^{13} \mathrm{C}-\mathrm{NMR}$ of dendrimer-glutamine.

Abbreviation: NMR, nuclear magnetic resonance. similar to ${ }^{99 \mathrm{~m}} \mathrm{Tc}$ citrate, ${ }^{36}$ the square pyramidal structure of the complexes was formed by an oxygen atom at the apex and four oxygen atoms in the corners. The oxidation state of the complex is $\mathrm{Tc}^{5+}$. RCP was also confirmed using $\gamma$ well-type counter. Data obtained by examining the chromatograms represented that the radiolabeled nanoconjugate with the efficiency of $94 \%$ was successfully produced.

\section{Lipophilicity and stability tests}

In vitro stability tests performed in human serum at $37^{\circ} \mathrm{C}$ and in PBS at room temperature over 24 hours are shown in Figure 9. The complex showed only 5\%-6\% transchelation. It means that the radiolabeled complex was found to be sufficiently stable in human serum and PBS. Moreover, log $P$ (lipophilicity) value of the ${ }^{99 \mathrm{~m}} \mathrm{Tc}$ nanoconjugate was -0.34 .

\section{Scintigraphic images and biodistribution studies}

To evaluate the uptake of radiolabeled nanoconjugate in the tumor, SPECT scans of mice were acquired at different time points after injecting $3.7 \mathrm{MBq}$ of radiotracer. Figures 10 and 11 indicate the radiotracer accumulation at different hourly intervals after injection. Kinetic analysis demonstrated that the tumor-to-muscle ratio was $2.47 \pm 0.07,2.38 \pm 0.04$, and $2.8 \pm 0.05 \%$ injection dose/g 1,2 , and 3 hours after injection, respectively. Thyroid and heart uptakes were low. Other tissue studies showed low uptake of radiotracer except for the liver and kidneys. This presented the excretory route of the nanoconjugate. A blocking experiment with a saturating dose of glutamine $(10 \mathrm{mg} / \mathrm{mL})$ injected with radiolabeled nanoconjugate revealed a significant reduction in radiotracer uptake presented in Figure 12. Table 1 and Figure 13 summarize the biodistribution profile of ${ }^{99 \mathrm{~m}} \mathrm{Tc}$ nanoconjugate at different times. $P$-value $<0.05$ was considered statistically significant.

\section{Discussion}

Nanotechnology is considered as a potential technique for the delivery of imaging and therapeutic agents and is moving very fast from concept to reality. ${ }^{37,38}$ Interesting features of the dendrimers such as monodispersity index, three-dimensional globular shapes, and surface functionalities have gained much attention for drug carriers and radioisotope imaging. ${ }^{39}$ According to the multifunctionality of the dendrimer it can form a complex with a large number of radioisotopes and thus can facilitate using the lower doses of radiotracer. ${ }^{40}$

With the use of conjugates such as amino acid conjugates, which can actively target tumor cells, effective imaging can be obtained. ${ }^{41-43}$ Above all, glutamine has drawn much 


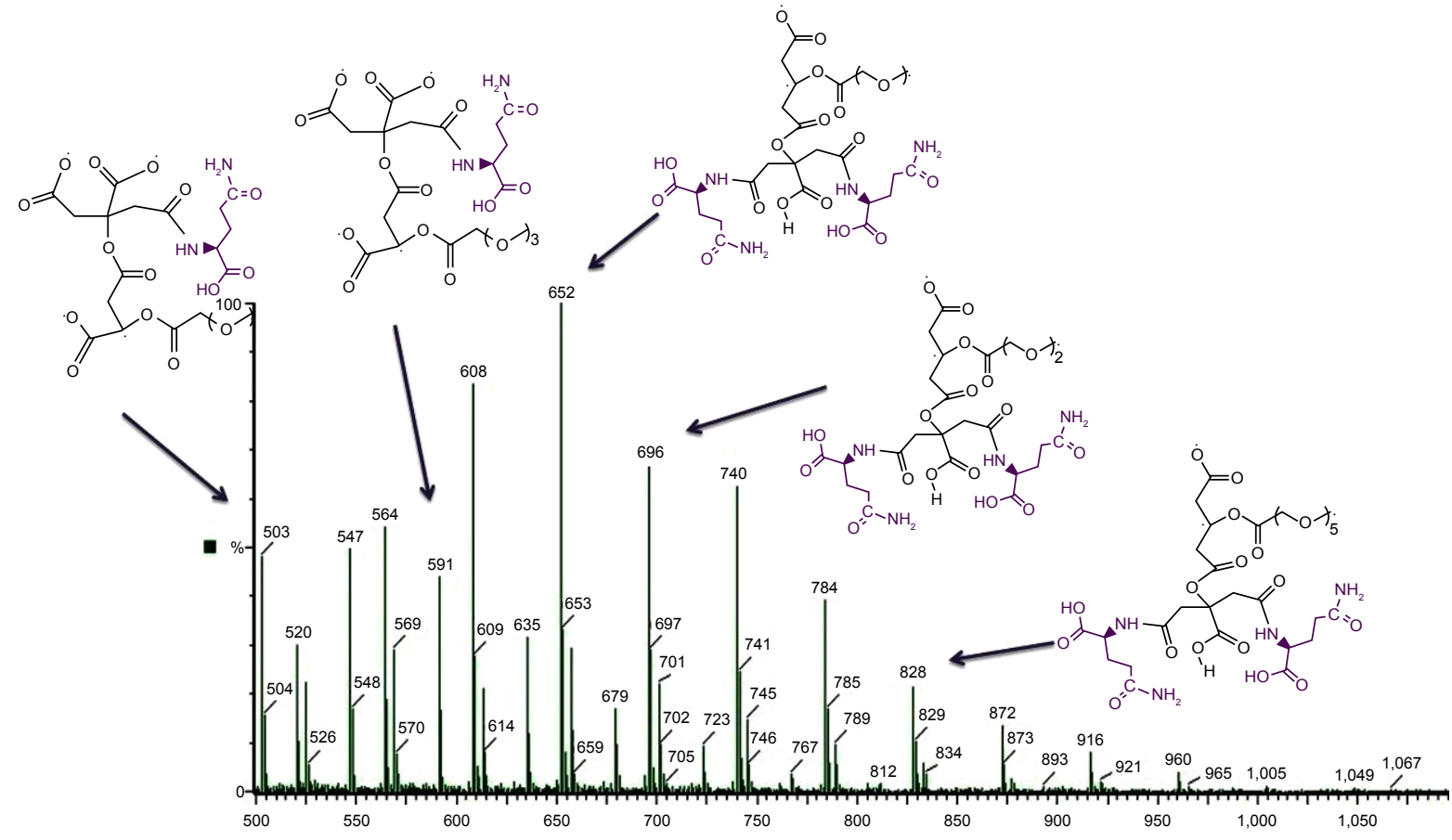

Figure 3 Liquid chromatography-mass spectroscopy of glutamine conjugated to dendrimer- $\mathrm{G}_{2}$.

attention owing to the cell metabolism association. ${ }^{44} \mathrm{~A}$ study describing ${ }^{13} \mathrm{~N}$-glutamine as a satisfactory imaging agent for malignant tumors has been reported in $1977 .{ }^{45}$ In this context, ${ }^{18} \mathrm{~F}$-glutamine has been synthesized by Ploessl et al in 2012 as a tumor metabolic radiotracer. They reported that ${ }^{18} \mathrm{~F}$-glutamine had fast uptake in tumor and muscle but had higher background radioactivity and represented apparent uptake in the skeleton. Defluorination and bone marrow uptake of the tracers can be the main cause of the results obtained. ${ }^{46}$

This study is focused on synthesizing ${ }^{99 \mathrm{~m}} \mathrm{Tc}$ dendrimer- $\mathrm{G}_{2}$ and conjugating it to the glutamine. Successful preparation

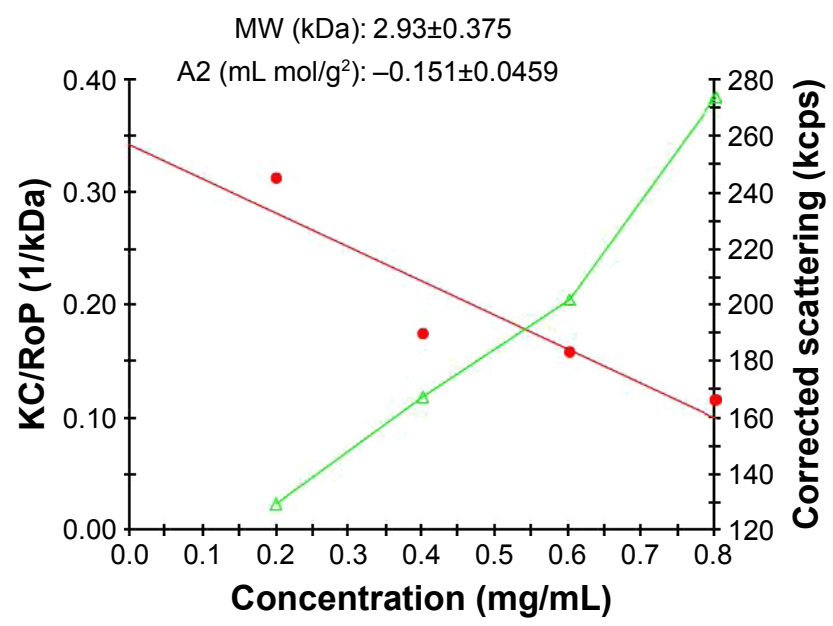

Figure 4 Debye plot of glutamine conjugated to dendrimer- $\mathrm{G}_{2}$. and high-efficiency synthesis of the nanoconjugate were confirmed by FT-IR, ${ }^{1} \mathrm{H}-\mathrm{NMR},{ }^{13} \mathrm{C}-\mathrm{NMR}$, and LC-MS spectra. The size and morphology of the nanoconjugate and the intact dendrimer were characterized using AFM technique. The AFM graphs clearly showed an increase in size of the nanoconjugate compared to the intact dendrimer. The morphologic status of the nanoconjugate and the intact dendrimer was completely visualized.

Reduction of the conjugate's surface charge and elevation of the conjugate's size acquired from DLS in comparison with intact dendrimer confirmed the synthesis of conjugate. By comparing the molecular weights of dendrimer- $\mathrm{G}_{2}$, glutamine, and dendrimer conjugates obtained from SLS technique, it is expected that around six glutamines conjugated to each particle of dendrimer. RCP demonstrated the $94 \%$ radiolabeling efficiency. In vitro stability study up to 24 hours confirmed that the radiolabeled complex was found to be sufficiently stable in human serum and PBS. Interestingly, cytotoxicity study represented that no toxicity was observed at the highest dose $(13.5 \mathrm{mg} / \mathrm{mL})$ both on cancer and normal cell lines. Moreover, data yielded by the apoptosis/ necrosis assay presented the mostly nontoxic nature of the nanoconjugate after 48 hours. In vitro cellular uptake of anionic dendrimer published in our previous study ${ }^{47}$ showed the greater ability of the ${ }^{99 \mathrm{~m}} \mathrm{Tc}$ nanoconjugate to enter cells. No cytotoxicity, high in vitro stability and cellular uptake of the nanocarrier supported its use in cancer imaging. 
A
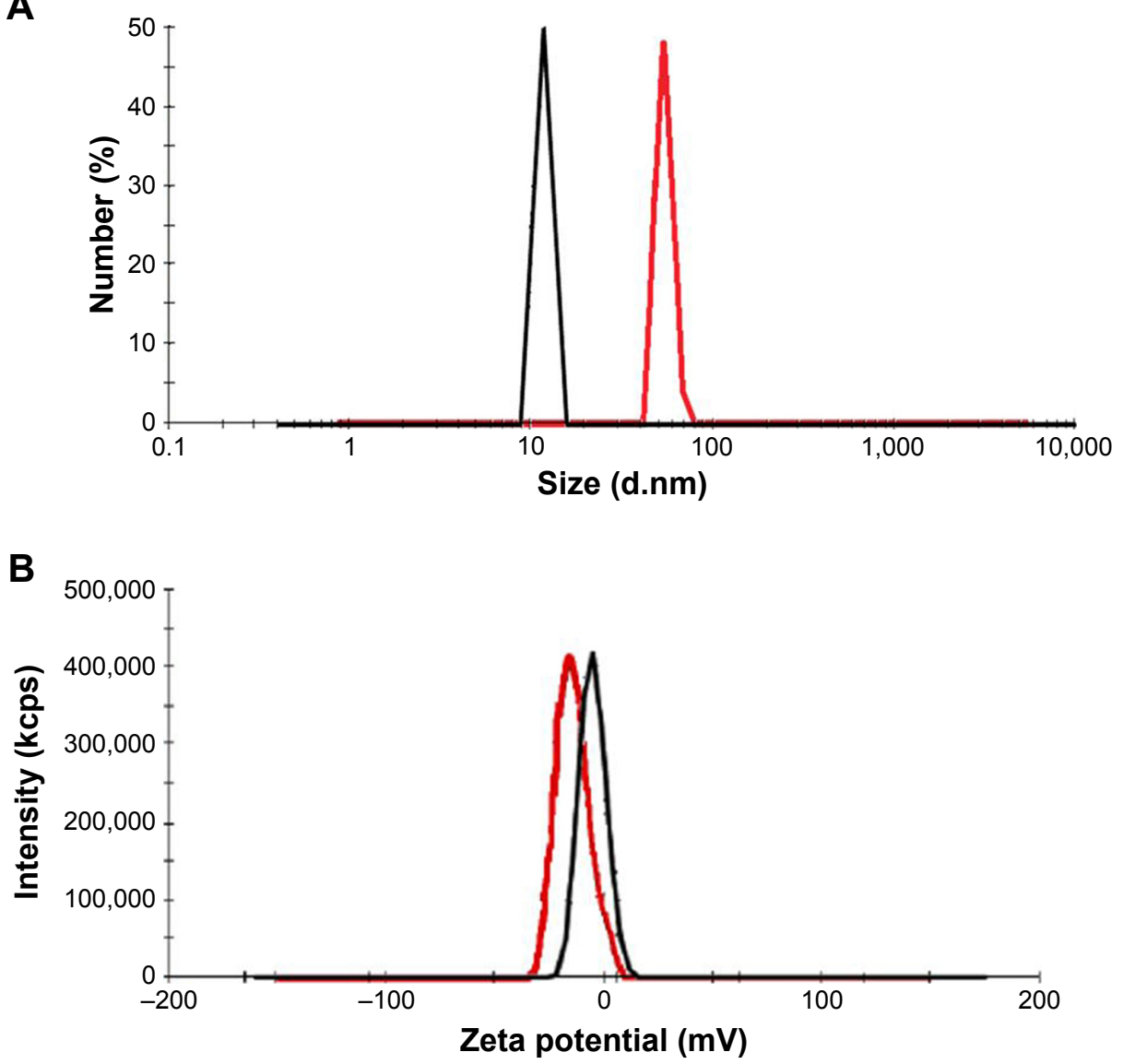

Figure 5 (A) Size and (B) zeta potential. Red and black colors show the nanoconjugate and intact dendrimer, respectively.

A

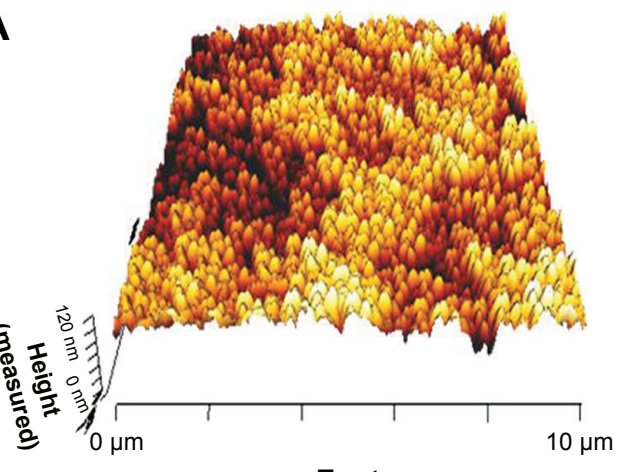

Fast

B

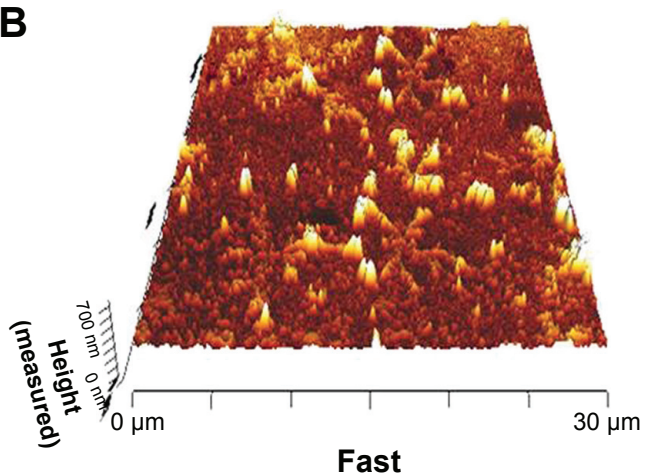

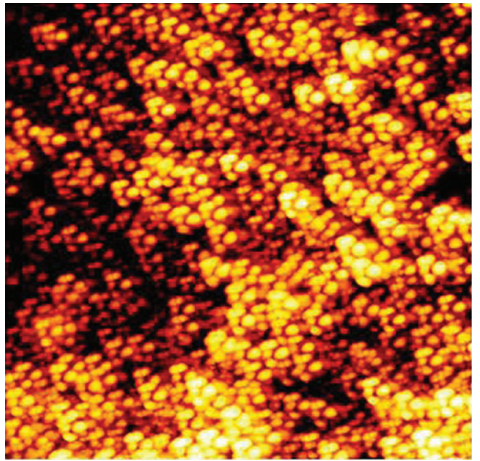

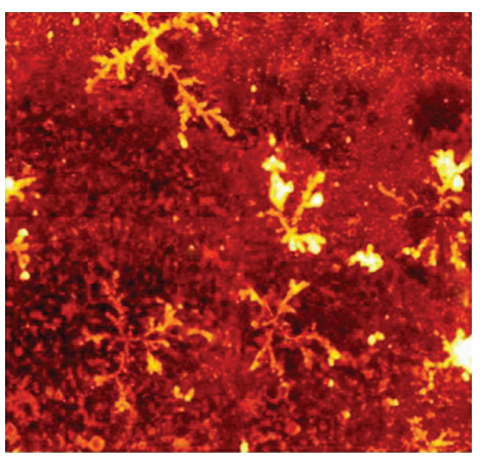

Figure 6 Atomic force microscopy image of the $(\mathbf{A})$ dendrimer and $(\mathbf{B})$ nanoconjugate. 

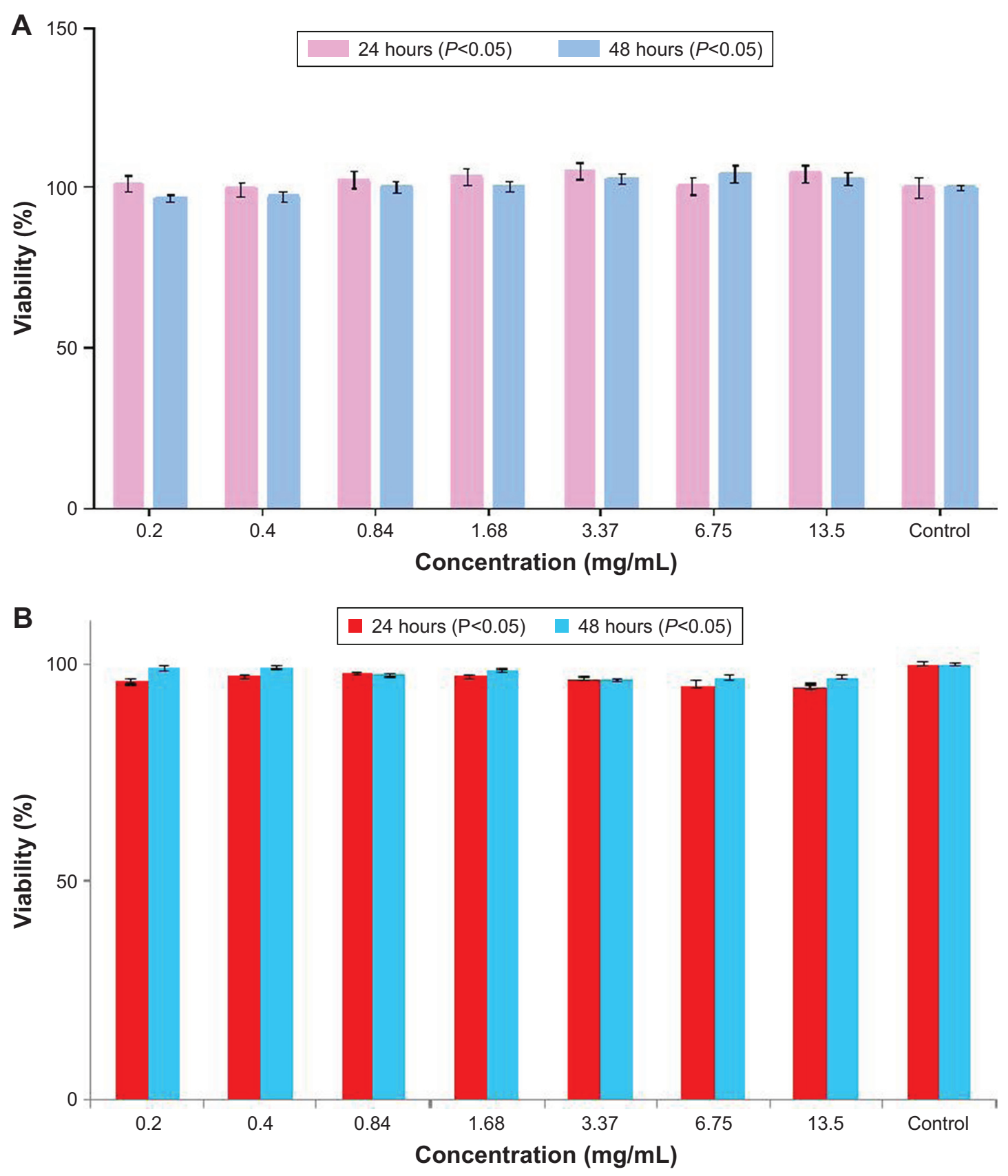

Figure 7 XTT assay: (A) A549 and (B) HEK-293 cells were exposed to the nanoconjugate for 24 and 48 hours.

\section{Cells treated with glutamine-dendrimer}
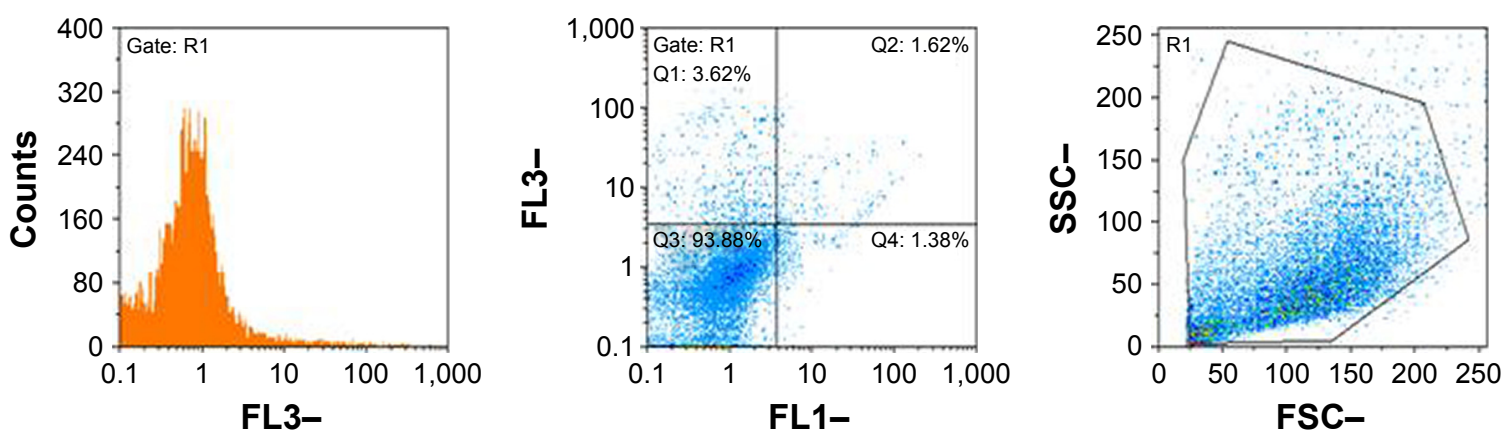

Figure 8 Apoptosis/necrosis assay plots of A549 cells treated with $5.5 \mathrm{mg} / \mathrm{mL}$ of the nanoconjugate after 48 hours of incubation time. 


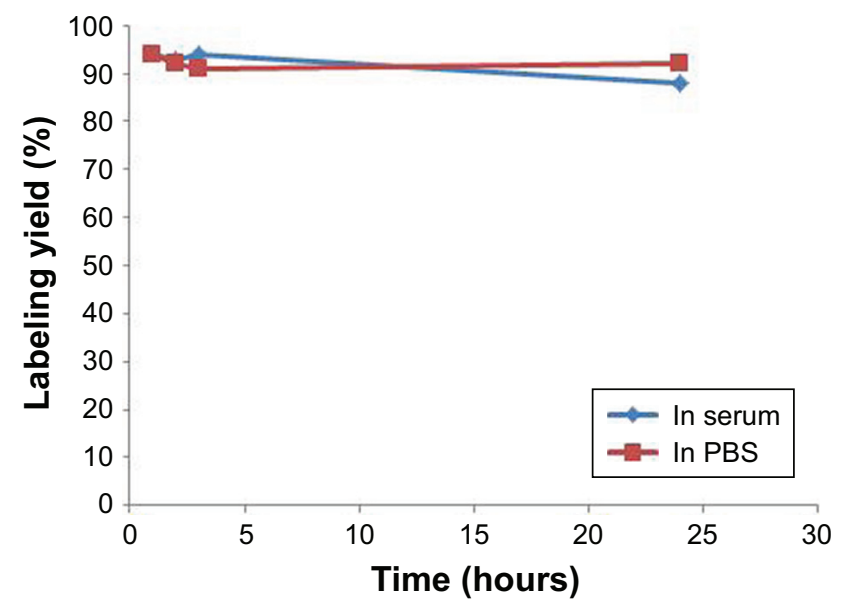

Figure 9 In vitro stability of ${ }^{99 \mathrm{~m}} \mathrm{Tc}$ nanoconjugate complex in human serum at $37^{\circ} \mathrm{C}$ and PBS at room temperature.

Abbreviation: PBS, phosphate buffered saline.

Biodistribution studies showed that the radioactivity was higher in the kidney. This suggests that the major direction of excretion of the radiotracer is through kidneys and the lipophilicity characteristic of nanoconjugate support our argument. Besides this, there was a high radioactivity uptake in the liver at the first hour. This finding might be because of the tendency of the dendrimer itself and glutamine nature of the nano-conjugate. Subsequently, quick washout can be confirmed by increasing the radioactivity in the intestine after 2 hours. Remarkably, results showed that no significant radioactivity was observed in the thyroid, stomach, and bone marrow, which demonstrates high stability of ${ }^{99 \mathrm{~m}} \mathrm{Tc}$ nanoconjugate as it is shown in serum stability test. Additionally, low-level uptake in thyroid and stomach represents that the free pertechnetate was quantitatively negligible and the labeling process was done perfectly. By comparing the radiotracer uptake in tumor and the surrounding tissues, higher radioactivity in tumor indicates that glutamine specifically targets radiotracer in the tumor site. In comparison to radiolabeled ${ }^{18} \mathrm{~F}$-glutamine, ${ }^{46}$ this novel radiolabeled nanoconjugate showed a noticeable biodistribution, possibly due to its lower molecular weight, increased solubility, and stable chelating capacity of the conjugate. Furthermore, the conjugate represented a substantial tumor uptake pattern because of the multitargeting nature of glutamine. A question that crosses the mind is how this carrier is cleared from organs. It is because of citric acid branches of the dendrimer, which can participate in TCA cycle and metabolize in the living cells. Finally, blocking experiment indicated reduced tumor uptake of the radiotracer in the presence of a blocking dose of glutamine amino acid.

The valuable prospects of ${ }^{99 \mathrm{~m}} \mathrm{Tc}$ nanoconjugate include biocompatibility, biodegradability, more water solubility of the nanocarrier, cost effectiveness and availability of ${ }^{99 \mathrm{~m}} \mathrm{Tc}$,

\section{A}
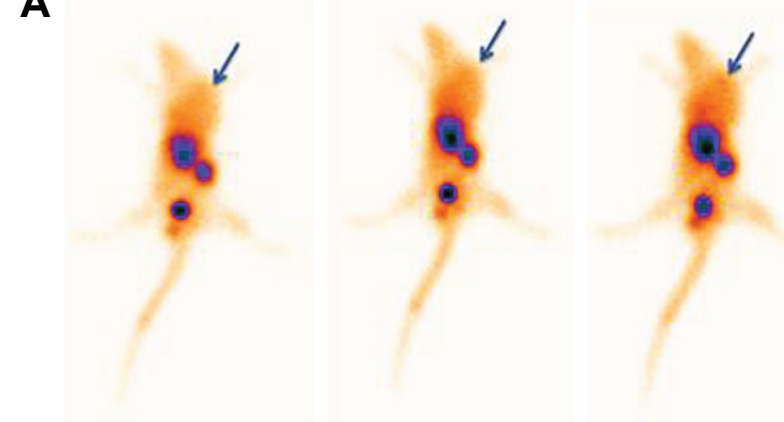

\section{B}

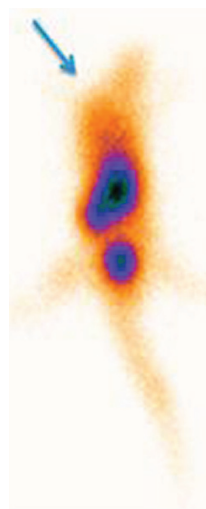

10 minutes

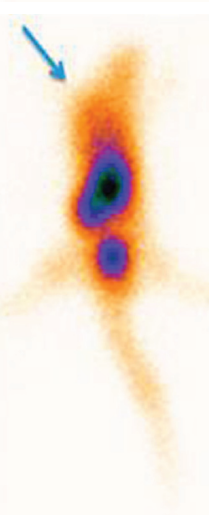

30 minutes

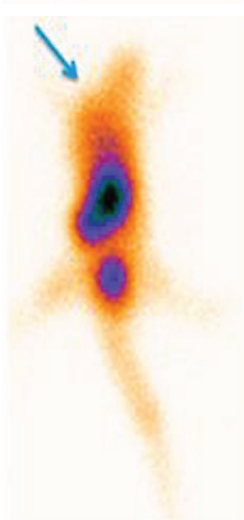

45 minutes
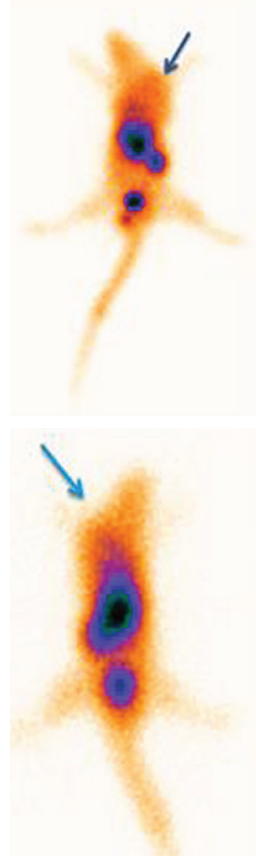

60 minutes

Figure 10 Planar images with ${ }^{99 \mathrm{~m} T c}$ nanoconjugate in mice acquired at different time intervals up until I hour after injection: (A) anterior, (B) posterior. The arrows indicate the tumor site. 


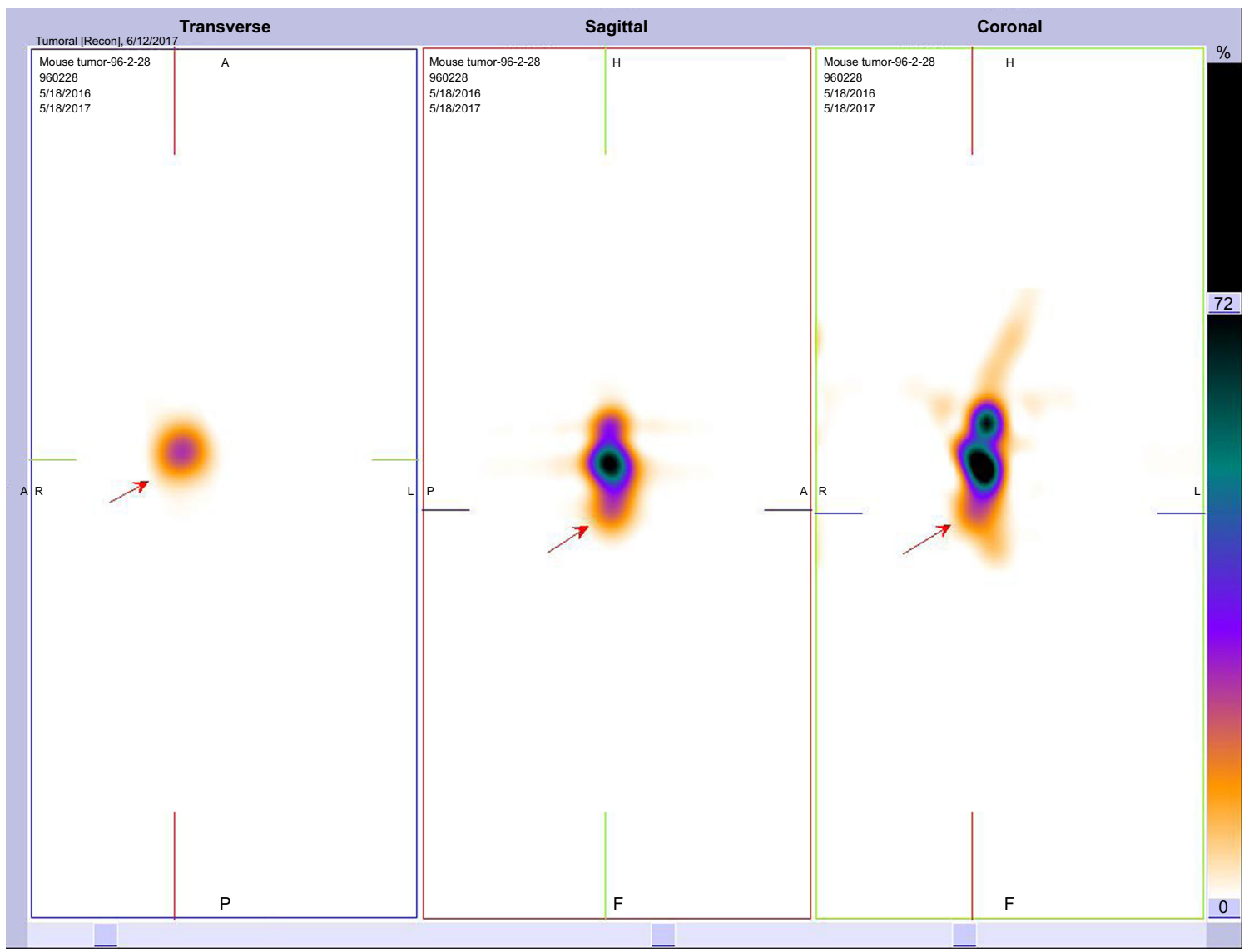

Figure I I Transverse, sagittal and coronal imaging of nude mice bearing A549 tumor I hour after injection of $3.7 \mathrm{MBq}$ of radiolabeled nanoconjugate. Arrows indicate the tumor position.

good potential of citric acid to form complex perfectly by ${ }^{99 \mathrm{~m}} \mathrm{Tc}$, no cytotoxicity, great in vitro stability, and also good cellular uptake. These findings suggest that in the near future this radiotracer can be used as a radioisotope delivery
A

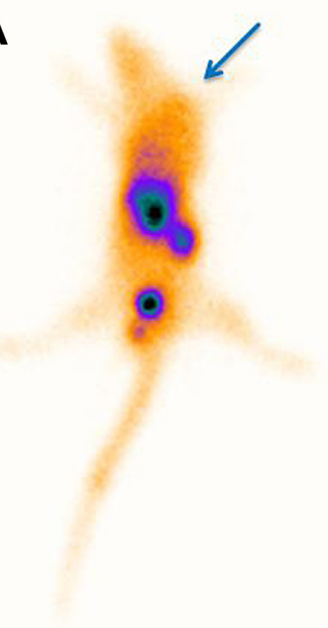

B

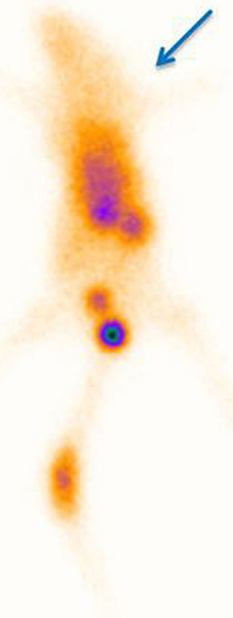

Figure 12 Tumor imaging of nude mice bearing A549 tumor I hour after injection of $3.7 \mathrm{MBq}$ of ${ }^{99 \mathrm{~m}} \mathrm{Tc}$ nanoconjugate $(\mathbf{A})$ without and $(\mathbf{B})$ with coadministration of $10 \mathrm{mg} / \mathrm{mL}$ of glutamine (glutamine blocking). The arrows indicate the tumor site. agent to target tumor tissues. It is obvious that more studies need to be done to understand the whole characteristics of the nanoconjugate. However, these findings alone are very interesting to understand the use of this nanoconjugate in cancer molecular imaging.

Table I Biodistribution profile of nanoconjugate at different times (dose per gram of tissue). Data expressed as percentage $\mathrm{ID} / \mathrm{g} \pm \mathrm{SD}(\mathrm{n}=3)$

\begin{tabular}{llll}
\hline & $\mathbf{I} \mathbf{h} \% \mathbf{I D} / \mathbf{g}$ & $\mathbf{2} \mathbf{h} \% \mathbf{I D} / \mathbf{g}$ & $\mathbf{3} \mathbf{h} \% \mathbf{I D} / \mathbf{g}$ \\
\hline Liver & $3.23 \pm 0.14$ & $2.88 \pm 0.13$ & $1.5 \pm 0.15$ \\
Kidney & $4.57 \pm 0.03$ & $3.7 \mathrm{I} \pm 0.13$ & $2.64 \pm 0.12$ \\
Lung & $1.88 \pm 0.02$ & $1.39 \pm 0.07$ & $0.91 \pm 0.07$ \\
Heart & $3.90 \pm 0.02$ & $3.83 \pm 0.009$ & $2.10 \pm 0.03$ \\
Blood & $1.92 \pm 0.12$ & $1.15 \pm 0.0 \mathrm{I}$ & $0.50 \pm 0.1$ \\
Thyroid & $0.7 \mathrm{I} \pm 0.13$ & $0.50 \pm 0.06$ & $0.46 \pm 0.07$ \\
Spleen & $1.36 \pm 0.004$ & $1.54 \pm 0.03$ & $0.84 \pm 0.15$ \\
Intestine & $0.76 \pm 0.06$ & $2.13 \pm 0.02$ & $1.90 \pm 0.09$ \\
Stomach & $0.68 \pm 0.03$ & $0.49 \pm 0.1$ & $0.3 \mathrm{I} \pm 0.15$ \\
Bone (femur) & $0.43 \pm 0.04$ & $0.21 \pm 0.06$ & $0.14 \pm 0.08$ \\
Muscle & $2.06 \pm 0.08$ & $2.85 \pm 0.07$ & $2.28 \pm 0.05$ \\
Tumor & $5.10 \pm 0.02$ & $6.8 \mathrm{I} \pm 0.01$ & $6.4 \pm 0.002$ \\
Tumor/muscle & $2.47 \pm 0.07$ & $2.38 \pm 0.04$ & $2.8 \pm 0.05$ \\
\hline
\end{tabular}

Abbreviation: ID, injection dose. 


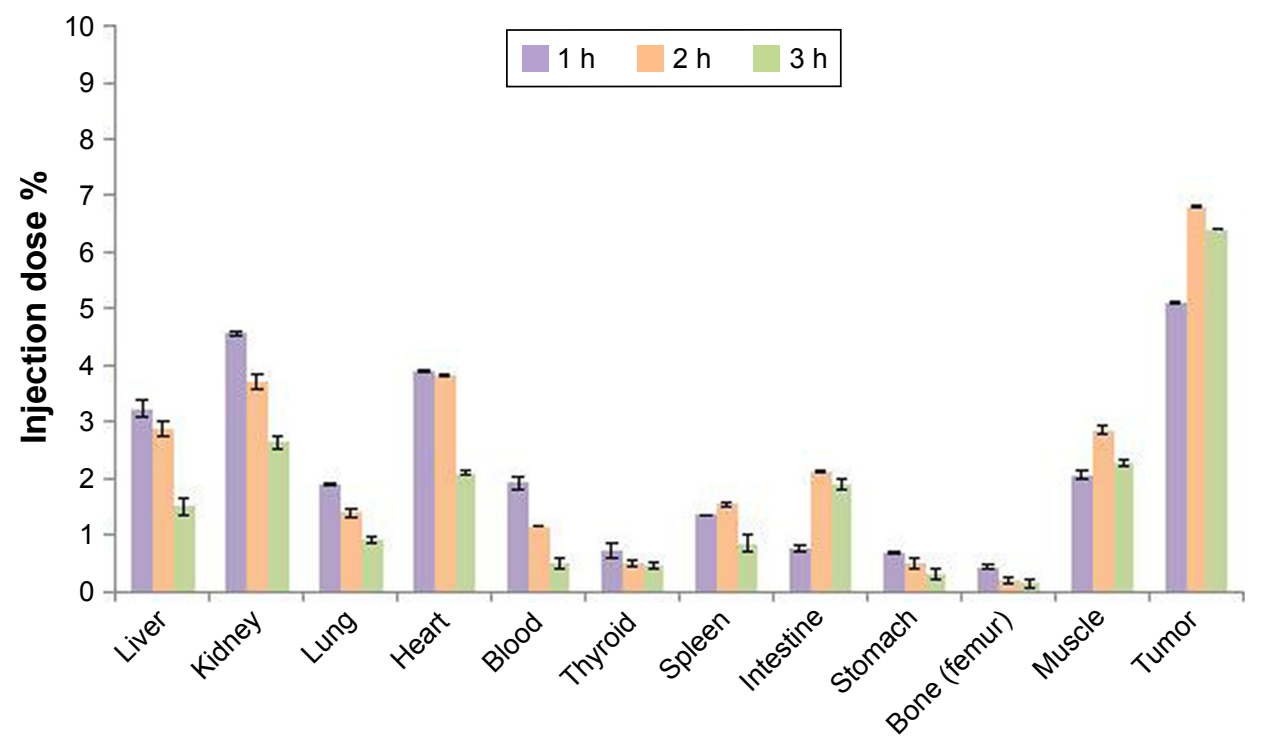

Figure 13 Biodistribution profile of nanoconjugate at different time intervals (dose per gram of tissue). $P$-value $<0.05$ was observed among various tissues.

\section{Conclusion}

The results obtained in this study represent that citric acidbased PEG dendrimer- $\mathrm{G}_{2}$ was successfully synthesized with proper characteristics for in vivo applications. Chelator-free radiolabeling of dendrimer with ${ }^{99 \mathrm{~m}} \mathrm{Tc}$ was performed with high-yield and stable complexes. Biodistribution studies showed a higher uptake in the tumor tissue in comparison to other organs. The present results may provide a potential application of the radiolabeled nanostructure in the development of SPECT tumor imaging.

\section{Acknowledgments}

Tehran University of Medical Sciences supported this study. The authors wish to thank all the technicians who provided support during the experiments.

\section{Disclosure}

The authors report no conflict of interest in this work.

\section{References}

1. Ma X, Yu H. Global burden of cancer. Yale J Biol Med. 2006;79(3-4): 85-94.

2. Goldsmith SJ, Kostakoglu L. Nuclear medicine imaging of lung cancer. Radiol Clin North Am. 2000;38(3):511-524.

3. Mariani G, Bruselli L, Kuwert T, et al. A review on the clinical uses of SPECT/CT. Eur J Nucl Med Mol Imaging. 2010;37(10):1959-1985.

4. Galbán CJ, Galbán S, van Dort ME, et al. Applications of molecular imaging. Prog Mol Biol Transl Sci. 2010;95:237-298.

5. Ekblad T, Tran T, Orlova A, et al. Development and preclinical characterisation of $99 \mathrm{mTc}-$ labelled Affibody molecules with reduced renal uptake. Eur J Nucl Med Mol Imaging. 2008;35(12):2245-2255.

6. Liu S, Edwards DS. 99mTc-Labeled Small Peptides as Diagnostic Radiopharmaceuticals. Chem Rev. 1999;99(9):2235-2268.

7. Salata O. Applications of nanoparticles in biology and medicine. J Nanobiotechnology. 2004;2(1):3-3.
8. Padmanabhan P, Kumar A, Kumar S, Chaudhary RK, Gulyás B. Nanoparticles in practice for molecular-imaging applications: An overview. Acta Biomater. 2016;41:1-16.

9. Snehalatha M, Venugopal K, Saha RN, Babbar AK, Sharma RK. Etoposide loaded PLGA and PCL nanoparticles II: biodistribution and pharmacokinetics after radiolabeling with Tc-99m. Drug Deliv. 2008;15(5):277-287.

10. Barrett T. Dendrimers Application Related to Bioimaging. IEEE Eng Med Biol Mag. 2009;28(1):12-22.

11. Samad A, Alam MI, Saxena K. Dendrimers: a class of polymers in the nanotechnology for the delivery of active pharmaceuticals. Curr Pharm Des. 2009;15(25):2958-2969.

12. Zhang Y, Sun Y, Xu X, et al. Synthesis, biodistribution, and microsingle photon emission computed tomography (SPECT) imaging study of technetium-99m labeled PEGylated dendrimer poly(amidoamine) (PAMAM)folic acid conjugates. $J$ Med Chem. 2010;53(8):3262-3272.

13. Zhao L, Zhu J, Cheng Y, et al. Chlorotoxin-Conjugated Multifunctional Dendrimers Labeled with Radionuclide 131I for Single Photon Emission Computed Tomography Imaging and Radiotherapy of Gliomas. ACS Appl Mater Interfaces. 2015;7(35):19798-19808.

14. Sato N, Kobayashi H, Saga T, et al. Tumor targeting and imaging of intraperitoneal tumors by use of antisense oligo-DNA complexed with dendrimers and/or avidin in mice. Clin Cancer Res. 2001;7(11): 3606-3612.

15. Seo JW, Baek H, Mahakian LM, et al. 64Cu-labeled LyP-1-dendrimer for PET-CT imaging of atherosclerotic plaque. Bioconjug Chem. 2014; 25(2):231-239.

16. Namazi H, Adeli M. Dendrimers of citric acid and poly (ethylene glycol) as the new drug-delivery agents. Biomaterials. 2005;26(10): $1175-1183$.

17. Alavidjeh MS, Haririan I, Khorramizadeh MR, Ghane ZZ, Ardestani MS, Namazi H. Anionic linear-globular dendrimers: biocompatible hybrid materials with potential uses in nanomedicine. J Mater Sci Mater Med. 2010;21(4):1121-1133.

18. Ardestani MS, Fordoei AS, Abdoli A, et al. Nanosilver based anionic linear globular dendrimer with a special significant antiretroviral activity. J Mater Sci Mater Med. 2015;26(5):179.

19. Khosroshahi AG, Amanlou M, Sabzevari O, et al. A comparative study of two novel nanosized radiolabeled analogues of methionine for SPECT tumor imaging. Curr Med Chem. 2013;20(1):123-133.

20. Naeini AT, Adeli M, Vossoughi M. Poly(citric acid)-blockpoly(ethylene glycol) copolymers - new biocompatible hybrid materials for nanomedicine. Nanomedicine. 2010;6(4):556-562. 
21. Namazi H, Toomari Hamrahloo Y. Novel PH Sensitive Nanocarrier Agents Based on Citric Acid Dendrimers Containing Conjugated B-Cyclodextrins. Adv Pharm Bull. 2011;1(1):40-47.

22. Altiparmak B, Lambrecht FY, Bayrak E, Durkan K. Design and synthesis of $99 \mathrm{mTc}$-citro-folate for use as a tumor-targeted radiopharmaceutical. Int J Pharm. 2010;400(1-2):8-14.

23. Jain K, Kesharwani P, Gupta U, Jain NK. Dendrimer toxicity: Let's meet the challenge. Int J Pharm. 2010;394(1-2):122-142.

24. del Amo EM, Urtti A, Yliperttula M. Pharmacokinetic role of L-type amino acid transporters LAT1 and LAT2. Eur J Pharm Sci. 2008;35(3): 161-174.

25. Brand K. Glutamine and glucose metabolism during thymocyte proliferation. Pathways of glutamine and glutamate metabolism. Biochem J. 1985;228(2):353-361.

26. Smith RJ. Glutamine metabolism and its physiologic importance. JPEN J Parenter Enteral Nutr. 1990;14(4 Suppl):40S-44S.

27. Wise DR, Thompson CB. Glutamine addiction: a new therapeutic target in cancer. Trends Biochem Sci. 2010;35(8):427-433.

28. Ali I, Wani WA, Haque A, Saleem K. Glutamic acid and its derivatives: candidates for rational design of anticancer drugs. Future Med Chem. 2013;5(8):961-978.

29. Wang Q, Hardie RA, Hoy AJ, et al. Targeting ASCT2-mediated glutamine uptake blocks prostate cancer growth and tumour development. J Pathol. 2015;236(3):278-289.

30. Peng T, Liu K, Gao L, et al. Poly (1- $\gamma$-glutamylglutamine) Polymer Enhances Doxorubicin Accumulation in Multidrug Resistant Breast Cancer Cells. Molecules. 2016;21(6):720.

31. Liu X, Liu J, Guan Y, et al. Establishment of an orthotopic lung cancer model in nude mice and its evaluation by spiral CT. J Thorac Dis. 2012; 4(2):141-145.

32. Assadi A, Najafabadi VS, Shandiz SA, et al. Novel chlorambucilconjugated anionic linear-globular PEG-based second-generation dendrimer: in vitro/in vivo improved anticancer activity. Onco Targets Ther. 2016;9:5531-5543.

33. Amin KC, Saha GB, Go RT. A rapid chromatographic method for quality control of technetium-99m-bicisate. J Nucl Med Technol. 1997; 25(1):49-51.

34. Decristoforo C. Quality Control Methods of 99mTc Pharmaceuticals. Zolle I. In: Technetium-99m Pharmaceuticals: Preparation and Quality Control in Nuclear Medicine. Berlin, Heidelberg: Springer Berlin Heidelberg; 2007:123-150.
35. Bancos S, Tsai D-H, Hackley V, Weaver JL, Tyner KM. Evaluation of Viability and Proliferation Profiles on Macrophages Treated with Silica Nanoparticles In Vitro via Plate-Based, Flow Cytometry, and Coulter Counter Assays. ISRN Nanotechnology. 2012;2012(1):1-11.

36. Russell CD, Speiser AG. Complexes of technetium with hydroxycarboxylic acids: gluconic, glucoheptonic, tartaric, and citric. J Nucl Med. 1980;21(11):1086-1090.

37. Koo OM, Rubinstein I, Onyuksel H. Role of nanotechnology in targeted drug delivery and imaging: a concise review. Nanomedicine: Nanotechnology. Biology and Medicine. 2005;1(3):193-212.

38. Peer D, Karp JM, Hong S, Farokhzad OC, Margalit R, Langer R. Nanocarriers as an emerging platform for cancer therapy. Nat Nanotechnol. 2007;2(12):751-760.

39. Cheng Y, Xu Z, Ma M, Xu T. Dendrimers as drug carriers: applications in different routes of drug administration. J Pharm Sci. 2008; 97(1):123-143.

40. Hong H, Zhang Y, Sun J, Cai W. Molecular imaging and therapy of cancer with radiolabeled nanoparticles. Nano Today. 2009;4(5): 399-413.

41. Ananieva E. Targeting amino acid metabolism in cancer growth and antitumor immune response. World J Biol Chem. 2015;6(4):281-289.

42. Hazari PP, Shukla G, Goel V, et al. Synthesis of specific SPECTradiopharmaceutical for tumor imaging based on methionine: $99 \mathrm{mTc}$ DTPA-bis(methionine). Bioconjug Chem. 2010;21(2):229-239.

43. Sinha D, Shukla G, Chuttani K, Chandra H, Mishra AK. Synthesis and biological evaluation of $(99 \mathrm{~m}) \mathrm{Tc}-\mathrm{DTPA}$-bis(His) as a potential probe for tumor imaging with SPECT. Cancer Biother Radiopharm. 2009; 24(5):615-620.

44. Dang CV, Hamaker M, Sun P, Le A, Gao P. Therapeutic targeting of cancer cell metabolism. J Mol Med. 2011;89(3):205-212.

45. Gelbard AS, Christie TR, Clarke LP, Laughlin JS. Imaging of spontaneous canine tumours with ammonia and L-glutamine labeled with N-13. J Nucl Med. 1977;18(7):718-723.

46. Ploessl K, Wang L, Lieberman BP, Qu W, Kung HF. Comparative evaluation of $18 \mathrm{~F}$-labeled glutamic acid and glutamine as tumor metabolic imaging agents. J Nucl Med. 2012;53(10):1616-1624.

47. Mohammadzadeh P, Cohan RA, Ghoreishi SM, Bitarafan-Rajabi A, Ardestani MS. AS1411 Aptamer-Anionic Linear Globular Dendrimer G2-Iohexol Selective Nano-Theranostics. Sci Rep. 2017;7(1):11832.
International Journal of Nanomedicine

\section{Publish your work in this journal}

The International Journal of Nanomedicine is an international, peerreviewed journal focusing on the application of nanotechnology in diagnostics, therapeutics, and drug delivery systems throughout the biomedical field. This journal is indexed on PubMed Central, MedLine, CAS, SciSearch $®$, Current Contents $\AA /$ Clinical Medicine,

\section{Dovepress}

Journal Citation Reports/Science Edition, EMBase, Scopus and the Elsevier Bibliographic databases. The manuscript management system is completely online and includes a very quick and fair peer-review system, which is all easy to use. Visit http://www.dovepress.com/ testimonials.php to read real quotes from published authors. 